\title{
Tumor characteristics and prognosis in familial breast cancer
}

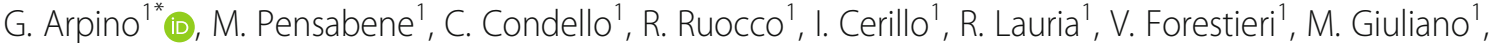 \\ C. De Angelis ${ }^{2}$, M. Montella ${ }^{3}$, A. Crispo $^{3}$ and S. De Placido ${ }^{1}$
}

\begin{abstract}
Background: Approximately 5-10\% of breast cancers are hereditary and their biology and prognosis appear to differ from those of sporadic breast cancers. In this study we compared the biological features and clinical characteristics of non metastatic breast cancer in patients with BRCA mutations versus patients with a family history suggesting hereditary breast cancer but without BRCA mutations (BRCA wild type) versus patients with sporadic disease, and correlated these findings with clinical outcome.

Methods: We retrieved the clinical and biological data of 33 BRCA-positive, 66 BRCA-wild type and 1826 sporadic breast cancer patients contained in a single institution clinical database between 1980 and 2012. Specifically, we recorded age, tumor size, nodal status, treatment type, pattern of relapse, second primary incidence, outcome (disease-free survival and overall survival), and biological features (estrogen receptor [ER], progesterone receptor $[\mathrm{PgR}]$, tumor grade, proliferation and c-erbB2 status). Median follow-up was 70 months.
\end{abstract}

Results: BRCA-positive patients were significantly younger than sporadic breast cancer patients, and less likely to be ER-, PgR- or c-erbB2-positive than women with BRCA-wild type or sporadic breast cancer. Tumor size and grade, nodal status and proliferation did not differ among the three groups. Rates of radical mastectomy were 58, 42 and $37 \%$, and those of conservative surgery were 42,58 and $63 \%$ in women with BRCA-positive, BRCA-wild type and sporadic breast cancer $(p=0.03)$, respectively. The incidence of contralateral breast cancer was 12,14 and $0 \%$ $(p<0.0001)$ and the incidence of second primary tumors (non breast) was 9,1 and $2 \%(p<0.0001)$ in BRCA-positive, BRCA-wild type and sporadic breast cancer, respectively. Median disease-free survival in years was 29 in BRCA-wild type, 19 in BRCA-positive and 14 in sporadic breast cancer patients (log-rank =0.007). Median overall survival in years was not reached for BRCA-wild type, 19 for BRCA-positive and 13 for sporadic breast cancer patients (log-rank <0.0001). At multivariate analyses only BRCA-wild type status was related to a significant improvement in overall survival versus the sporadic breast cancer group $(H R=0,51 ; 95 \% \mathrm{Cl}(0,28-0,93) p=0.028)$.

Conclusions: The biology and outcome of breast cancer differ between patients with BRCA mutations, patients with a family history but no BRCA mutations and patients with sporadic breast cancer.

\section{Background}

Carcinoma of the breast is a biologically heterogeneous disease. Approximately $5-10 \%$ of all breast cancers have a hereditary background. BRCA1 and BRCA2 mutations account for $25-28 \%$ of hereditary breast cancers [1]. Young women are more likely to have BRCA-associated breast cancer than to be affected by sporadic disease, and BRCA-positive cancers are usually high grade and

\footnotetext{
* Correspondence: grazia.arpino@unina.it

${ }^{1}$ Department of Clinical Medicine and Surgery, University of Naples Federico II, Naples, Italy

Full list of author information is available at the end of the article
}

lack hormone receptors [2]. Compared with sporadic cancer, the prognosis of BRCA-positive cancer has been reported to be worse $[3,4]$ not different $[5,6]$ or better [7]. In about $70 \%$ of families with aggregation of breast and ovarian cancers and a pedigree strongly suggesting hereditary breast cancer, the BRCA test was negative and no pathogenic mutation was identified [8-12]. This subgroup of familial non-BRCA mutated breast cancers are very heterogeneous and not well defined in terms of histopathological features, clinical presentation and prognosis. Moreover, little is known about the biological features of BRCA-mutated and of BRCA-wild type breast 
cancer in relation to their clinical outcome. Therefore, we compared the features of BRCA-mutated, BRCA-wild type and sporadic breast cancer recorded in a large database in the attempt to shed light on their biological phenotype and clinical behavior, and to obtain information that might aid clinical decision making and studies exploring the biological nature of this disease.

\section{Methods}

\section{Patients' characteristics}

From 1980 to 2012, patients with breast cancer presenting at our Department were screened for family history of cancer and referred to the genetic counseling service, if eligible. To be eligible for cancer genetic counseling, patients had to fulfill one of two criteria: 1) a personal history suggesting a genetic risk (i.e., early onset breast cancer, breast and ovarian cancer in the same subject, and multiple cancers besides breast and ovarian cancers in the same subject); and 2) a significant family history of breast and/or ovarian cancer defined as: (a) at least 2 cases of breast cancer in family members below the age of 50 years or ovarian, peritoneal or tubal cancer in family members at any age; (b) 3 cases of breast cancer or ovarian, peritoneal or tubal cancer in family members at any age; or (c) 1 case of breast cancer in a family member below the age of 50 years or bilateral breast cancer in a family member at any age. Cancer genetic counseling was conducted according to the model previously described [13].

Risk assessment was performed with two predictive models: the clinical criteria of Modena [14] and BRCApro $[15,16]$. Patients considered at high risk for a BRCA mutation according to the clinical criteria of Modena and/or a BRCApro test (total score $210 \%$ ) underwent genetic testing for BRCA1 and BRCA2 mutations [17, 18]. Mutation analysis was carried out at the Genetic Oncology Section, Division of Surgical, Molecular and Ultrastructural Pathology, University of Pisa. Genomic DNA was extracted from peripheral blood lymphocytes according to a standard protocol. Mutational screening of BRCA1 and BRCA2 was carried out by direct sequencing. DNA sequencing was carried out directly on PCR-purified products using the BigDye terminator v 3.1 sequencing kit (Applied Biosystems, Foster City, CA) and different primers (primer sequences available upon request). Capillary gel electrophoresis and data collection were carried out with an automated DNA sequencer (ABI PRISM 3100, Applera, Norwalk, CT). Sequence analyses were conducted with the Seq-Scape Software (Applied Biosystems). Mutation nomenclature for the BRCA1 and BRCA2 genes is as used in the BIC database according to the recommendations of GenBank [19].

Data were collected from 1946 women with stage I, IIA, IIB, IIIA or IIIB breast cancer at our Department between 1980 and 2012. Biological and clinical information for this analysis were extracted from a clinical database containing the patients' charts. No patient enrolled in this study had received bilateral prophylactic mastectomy or prophylactic oophorectomy. A total of 120 patients were eligible for genetic testing for BRCA1 and BRCA2 mutations, according to the criteria described above. The remaining 1826 patients were considered to have a sporadic breast cancer as no clear hereditary pattern was identified. These patients did not undergo genetic testing for BRCA1 and BRCA2 mutations.

Among the 120 patients with a known BRCA status, 33 women were positive for a BRCA1 and/or BRCA2 mutation (BRCA-positive), 66 women were negative for a BRCA1 and/or a BRCA2 mutation (BRCA-wild type) and were considered to have familial non-BRCA mutated breast cancer, and 21 patients had genetic alterations classified "variants of unknown significance". These patients were excluded from the present study because of the uncertain biologic or clinical relevance of these variants.

The clinical and pathological features of patients with BRCA-positive breast cancer were assessed and compared to those of patients with BRCA-wild type or sporadic breast cancer. Type of treatment, rates of relapse (local and distant), second primary and contralateral breast cancer onset, disease-free survival and overall survival were also compared among the three groups. Institutional Review Board approval was waived as all patients signed informed consent to anonymous data treatment for scientific purpose according to Italian law (art.13, D.lgs. 196/2003).

\section{Statistical analysis}

The patients' characteristics were compared using the $X^{2}$ test and an asymptotic Fisher's exact test for categorical variables and $t$ tests for continuous variables. Diseasefree survival was calculated as the time from diagnosis to first recurrence (local or distant); cause-specific survival was calculated as the time from diagnosis to death for that cancer, or to censoring if the patient was alive at the last follow-up. Rates of recurrence and second primaries of the three groups (BRCA-positive, BRCA-wild type, sporadic breast cancer) were calculated by dividing the number of events by the total persontime at risk. Unadjusted relative risks (rate ratios) were obtained by dividing the event rate in the screened group by the event rate in the symptomatic groups [20]. The univariate effect of key tumor characteristics on risk of recurrence and death was examined within each patient group. Overall and disease-free survival curves were constructed with Kaplan-Meier analyses and compared using the two-sided log-rank test. The SPSS statistical package version 20.0 (SPSS Inc, Chicago, IL) was used for statistical analysis. A $p$-value $<0.05$ was considered statistically significant. All patients enrolled in this study had been treated and followed up at our Department. 


\section{Results}

\section{Clinical and pathological characteristics}

The data of 1946 patients with non metastatic breast cancer were recorded in the database of the Breast Oncology Division of the University of Naples Federico II between 1980 and 2012. Of these, 1826 patients had sporadic breast cancer, 33 had BRCA-positive cancer (19 BRCA1-mutated and 14 BRCA2-mutated) and 66 had BRCA-wild type breast cancer. As shown in Table 1, BRCA-positive patients were significantly younger than sporadic breast cancer patients, and were less likely to be positive for estrogen receptor (ER), progesterone receptor (PgR) or human epidermal growth factor receptor (c-erbB2) than women with BRCA-wild type or sporadic breast cancer. In detail, in patients with BRCA-positive, BRCA-wild type and sporadic cancer, respectively, 54, 67 and $80 \%(p<0.0001)$ of tumors were ER-positive, 54, 68 and $74 \%(p=0.04)$ were PgRpositive, and 9,36 and $17 \%(p=0.01)$ were c-erbB2positive. No statistically significant difference in tumor size, nodal status, grading or proliferation, measured as Ki67, was observed among the three study groups. The type of local and systemic treatment of the primary tumor differed significantly among the three groups (Table 2). Radical mastectomy was more frequent among BRCApositive and BRCA-wild type patients (58\% vs. $42 \%$ vs. $37 \%$ in BRCA-positive vs. BRCA-wild type vs. sporadic breast cancer, $p<0.03)$. As expected from the distribution of ER, the rate of only chemotherapy as systemic

Table 1 Patient Demographics and Clinical Characteristics

\begin{tabular}{|c|c|c|c|c|c|c|c|}
\hline \multirow{3}{*}{ Number of patients ${ }^{a}$} & \multicolumn{2}{|c|}{ BRCA-positive } & \multicolumn{2}{|c|}{ BRCA-wild type } & \multicolumn{2}{|l|}{ Sporadic } & \multirow[t]{3}{*}{$p$-value } \\
\hline & 33 & & $\overline{66}$ & & 1826 & & \\
\hline & $\mathrm{N}$ & $\%$ & $\mathrm{~N}$ & $\%$ & $\mathrm{~N}$ & $\%$ & \\
\hline Age at diagnosis & & & & & & & $<0.0001$ \\
\hline$\leq 35$ & 14 & 43 & 11 & 16 & 102 & 6 & \\
\hline $36-45$ & 10 & 30 & 33 & 50 & 421 & 23 & \\
\hline $46-55$ & 5 & 15 & 11 & 17 & 547 & 30 & \\
\hline$\geq 56$ & 4 & 12 & 11 & 17 & 756 & 41 & \\
\hline Tumor size & $N=24$ & & $N=56$ & & $N=1560$ & & 0.79 \\
\hline$<=2 \mathrm{~cm}$ & 10 & 42 & 31 & 55 & 790 & 51 & \\
\hline$>2 \mathrm{~cm},<=5 \mathrm{~cm}$ & 12 & 50 & 20 & 36 & 652 & 42 & \\
\hline$>5$ & 2 & 8 & 5 & 9 & 118 & 7 & \\
\hline Nodal status & $N=28$ & & $N=59$ & & $N=1593$ & & 0.46 \\
\hline Node negative & 13 & 46 & 34 & 58 & 793 & 50 & \\
\hline Node positive & 15 & 54 & 25 & 42 & 800 & 50 & \\
\hline Tumor grade & $N=20$ & & $N=48$ & & $N=1435$ & & 0.07 \\
\hline 1 & 1 & 5 & 6 & 13 & 82 & 6 & \\
\hline 2 & 4 & 20 & 14 & 29 & 574 & 40 & \\
\hline 3 & 15 & 75 & 28 & 58 & 779 & 54 & \\
\hline ER status & $N=26$ & & $N=55$ & & $N=1545$ & & $<0.0001$ \\
\hline Positive & 14 & 54 & 37 & 67 & 1238 & 80 & \\
\hline Negative & 12 & 46 & 18 & 33 & 307 & 20 & \\
\hline PgR status & $N=26$ & & $N=54$ & & $N=1531$ & & 0.04 \\
\hline Positive & 14 & 54 & 37 & 68 & 1136 & 74 & \\
\hline Negative & 12 & 46 & 17 & 32 & 395 & 26 & \\
\hline Ki67 status & $N=21$ & & $N=29$ & & $N=1079$ & & 0.87 \\
\hline Low & 6 & 29 & 10 & 35 & 327 & 30 & \\
\hline High & 15 & 71 & 19 & 65 & 752 & 70 & \\
\hline cerb-B2 status & $N=22$ & & $N=33$ & & $N=1069$ & & 0.01 \\
\hline Negative & 20 & 91 & 21 & 64 & 884 & 83 & \\
\hline Positive & 2 & 9 & 12 & 36 & 185 & 17 & \\
\hline
\end{tabular}

$E R$ estrogen receptor, $P g R$ progesterone receptor

${ }^{a}$ The 21 patients carrying variants of unknown significance were excluded from the analysis. Comparisons were made by Chi-square test/asymptomatic Fisher's exact test 
Table 2 Type of treatments according to BRCA status

\begin{tabular}{|c|c|c|c|c|c|c|c|}
\hline & \multicolumn{2}{|c|}{ BRCA-positive } & \multicolumn{2}{|c|}{ BRCA-wild type } & \multicolumn{2}{|c|}{ Sporadic } & \multirow[t]{2}{*}{$p$-value } \\
\hline & $\bar{N}$ & $\%$ & $\bar{N}$ & $\%$ & $\bar{N}$ & $\overline{\%}$ & \\
\hline Type of surgery & \multicolumn{2}{|l|}{$N=33$} & \multicolumn{2}{|l|}{$N=64$} & \multicolumn{2}{|c|}{$N=1825$} & 0.03 \\
\hline Mastectomy & 19 & 58 & 27 & 42 & 670 & 37 & \\
\hline Conservative & 14 & 42 & 37 & 58 & 1155 & 63 & \\
\hline Adjuvant therapy & \multicolumn{2}{|l|}{$N=32$} & \multicolumn{2}{|l|}{$N=66$} & \multicolumn{2}{|c|}{$N=1826$} & $<0.0001$ \\
\hline No therapy & 3 & 9 & 16 & 24 & 88 & 5 & \\
\hline Only CT & 13 & 41 & 18 & 27 & 400 & 22 & \\
\hline Only HT & 4 & 13 & 15 & 23 & 437 & 24 & \\
\hline $\mathrm{CT}+\mathrm{HT}$ & 12 & 37 & 17 & 26 & 901 & 49 & \\
\hline
\end{tabular}

The 21 patients carrying variants of unknown significance were excluded from the analysis

$C T$ chemotherapy, HT hormone therapy

treatment was higher in BRCA-positive patients than in either BRCA-wild type or sporadic breast cancer patients $(41 \%$ vs. $27 \%$ vs. $22 \%)$. Rates of adjuvant hormone therapy without chemotherapy were lower in the BRCA-positive patients $(13 \%$ vs. $23 \%$ vs. $24 \%$ in BRCA-positive vs. BRCA-wild type vs. sporadic breast cancer patients), and fewer BRCA-wild type patients received chemotherapy followed by endocrine therapy ( $37 \%$ vs. $26 \%$ vs. $49 \%$ in BRCA-positive vs. BRCA-wild type vs. sporadic breast cancer patients) compared to the other two study groups. All the differences in the type of adjuvant systemic treatment delivered in the three study groups were statistically significant $(p<0.0001)$.

\section{Clinical outcomes}

The median follow-up time was 70 months (range: 13-421 months). The development of recurrence differed significantly among the three groups ( $27 \%$ vs. $33 \%$ vs. $29 \%$ in BRCA-positive vs. BRCA-wild type vs. sporadic breast cancer, respectively). In detail, BRCA-positive-breast cancer patients and BRCA-wild type breast cancer patients were more prone to develop contralateral breast cancer ( $12 \%$ vs. $14 \%$ vs. $0 \%$ in BRCA-positive vs. BRCA-wild type vs. sporadic breast cancer, respectively) and BRCA-positive breast cancer patients were more prone to develop second non-breast primary tumors ( $9 \%$ vs. $1 \%$ vs. $2 \%$ in BRCA-positive vs. BRCA-wild type vs. sporadicbreast cancer, respectively). All these data were statistically significant $(p<0.0001)$ (Table 3$)$.

Table 4 shows the recurrence rate and breast cancer mortality in relation to BRCA status. The recurrence rate was 35 per 1000 person-years (95\% CI 16-66), 31 per 1000 person-years (95\% CI 20-47) and 48 per 1000 person-years (95\% CI 45-53), and the rates of overall survival were 32 per 1000 person-years (95\% CI 15-59), 22 per 1000 personyears (95\% CI 13-35) and 40 per 1000 person-years (95\% CI 37-43) in BRCA-positive vs BRCA-wild type vs sporadic breast cancer. As shown in Fig. 1, disease-free survival differed significantly among the three groups (log-rank=
Table 3 Recurrence, contralateral breast cancer and second primary rates according to BRCA status

\begin{tabular}{|c|c|c|c|c|c|c|c|}
\hline & \multicolumn{2}{|c|}{ BRCA-positive } & \multicolumn{2}{|c|}{ BRCA-wild type } & \multicolumn{2}{|c|}{ Sporadic } & \multirow[t]{2}{*}{$p$-value } \\
\hline & $N$ & $\%$ & $\bar{N}$ & $\%$ & $N$ & $\%$ & \\
\hline & \multicolumn{2}{|c|}{$N=33$} & \multicolumn{2}{|c|}{$N=66$} & \multicolumn{2}{|c|}{$N=1826$} & $<0.0001$ \\
\hline No events & 17 & 52 & 34 & 51 & 1264 & 69 & \\
\hline Recurrence & 9 & 27 & 22 & 33 & 522 & 29 & \\
\hline Contralateral Breast & 4 & 12 & 9 & 14 & 6 & 0 & \\
\hline Second primary ${ }^{a}$ & 3 & 9 & 1 & 1 & 34 & 2 & \\
\hline
\end{tabular}

The 21 patients carrying variants of unknown significance were excluded from the analysis

${ }^{a}$ Second primaries are defined as all non breast second primaries

0.007). The median disease-free survival in years was 29 (16-42) for BRCA-wild type, 19 (10-28) for BRCA-positive and $14(13-15)$ for sporadic breast cancer patients. Overall survival differed significantly among the three groups (logrank <0.0001). Median overall survival in years was not reached for BRCA-wild type, 19 (12-26) for BRCA-positive and 13 (12-14) for sporadic breast cancer patients (Fig. 2). However, at multivariate analyses including all three study groups and adjusted for age, year of diagnosis, tumor stage at diagnosis and ER and PgR status, only BRCA-wild type status was related to a statistically significant improvement in overall compared to the sporadic breast cancer group $(\mathrm{HR}=0,51 ; 95 \%$ CI $0,28-0,93 ; p=0.028)$.

\section{Discussion}

Here we provide evidence that the presentation and outcome of breast cancer differ between patients with a strong family history, with or without a BRCA mutation, and patients with sporadic breast cancer. Consistent with previous reports [21-23], most of our BRCA-mutated patients were below the age of 35 years, whereas most patients with sporadic cancer were above the age of

Table 4 Recurrence and breast cancer mortality in relation to BRCA status

\begin{tabular}{llll}
\hline & $\begin{array}{l}\text { Person- } \\
\text { years }^{\mathrm{a}}\end{array}$ & $\begin{array}{l}\text { No. of } \\
\text { events }\end{array}$ & $\begin{array}{l}\text { Rate } \times 1000 \text { person-years } \\
(95 \% \mathrm{Cl})^{\mathrm{b}}\end{array}$ \\
\hline $\begin{array}{l}\text { DFS } \\
\text { BRCA-positive }\end{array}$ & 257 & 9 & $35(16-66)$ \\
$\begin{array}{l}\text { BRCA-wild } \\
\text { type }\end{array}$ & 702 & 22 & $31(20-47)$ \\
$\quad$ Sporadic & 12721 & 522 & $48(45-53)$ \\
$\begin{array}{l}\text { OS } \\
\text { BRCA-positive }\end{array}$ & 312 & 10 & $32(15-59)$ \\
BRCA-wild & 814 & 18 & $22(13-35)$ \\
type & 14943 & 598 & $40(37-43)$ \\
Sporadic
\end{tabular}

The 21 patients carrying variants of unknown significance were excluded from the analysis

Cl confidence interval, DFS disease-free survival, OS overall survival

a Rates were calculated from the reference date (i.e. date of diagnosis)

${ }^{\mathrm{b}}$ Confidence interval by Haenszel et al. JNCl 1962 


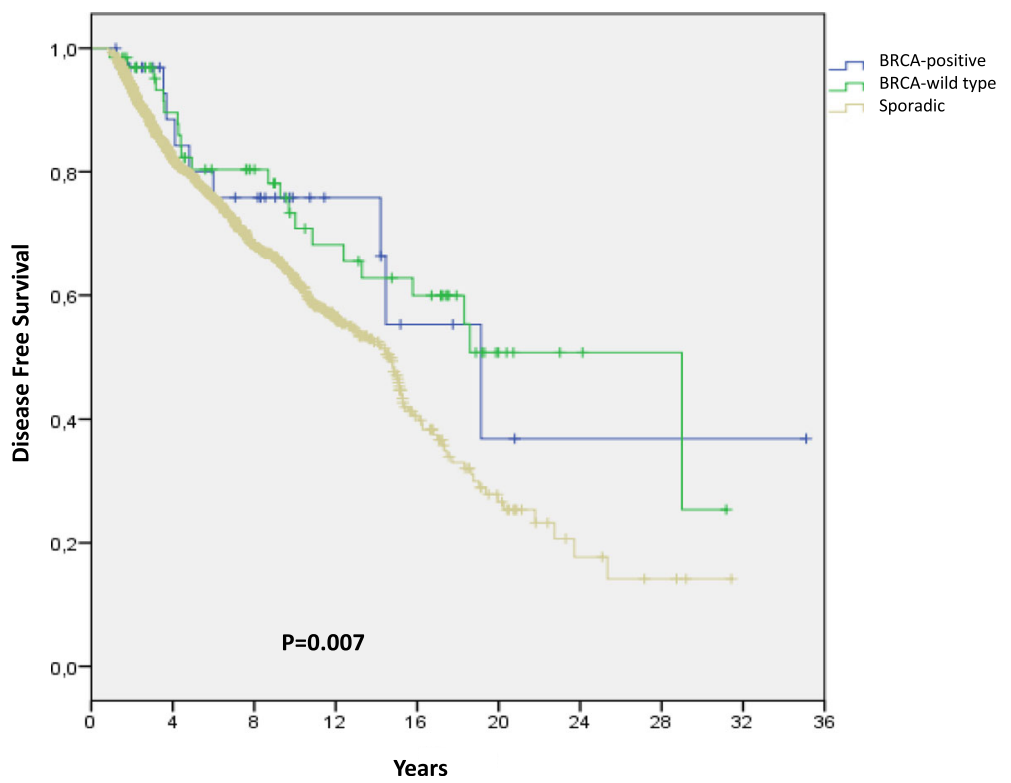

Fig. 1 Disease-free survival. Disease-free survival in patients with BRCA-positive, BRCA-wild type or sporadic breast cancer

46 years. The incidence of BRCA-wild type breast cancer was higher among women between the ages of 36 and 55 years. In terms of tumor characteristics, we found no difference in tumor size or nodal status at diagnosis among the three study groups. However, tumor biology differed depending on BRCA mutation status. BRCApositive breast cancers were more likely to be ER-negative and/or PgR-negative and less likely to display c-erbB2 overexpression than either BRCA-wild type or sporadic tumors. Interestingly, there was also a trend, albeit not significant, for BRCA-positive tumors to be grade 3 and to have a higher proliferation rate than the other two types of tumors. These data are consistent with previous studies showing that only a minority of BRCA1-mutated breast cancers have high ER expression rates or overexpress cerbB2 [24], and that most BRCA-mutated tumors are high-grade and have a higher proliferation fraction compared with sporadic tumors $[25,26]$.

BRCA-wild type breast cancers have often been reported to be low grade and have biologic features similar to those of sporadic cancers $[27,28]$. However, the data are not consistent. In the present study, we found higher c-erbB2

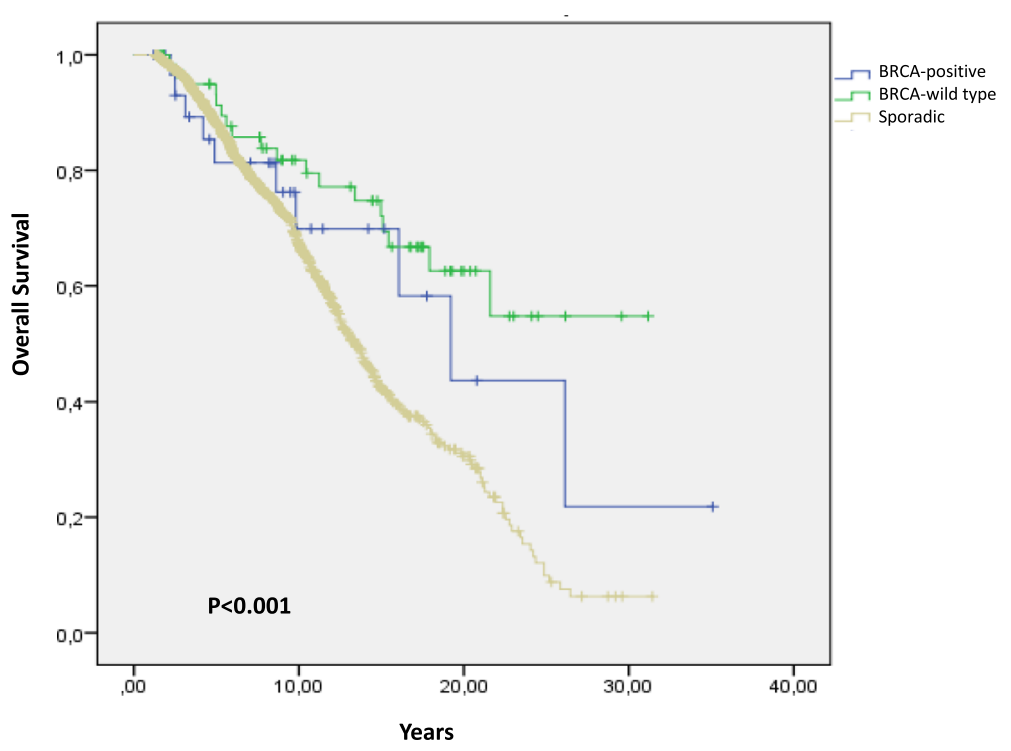

Fig. 2 Overall survival. Overall survival in patients with BRCA-positive, BRCA- wild type or sporadic breast cancer 
overexpression and a trend towards a higher incidence of grade 1 cancers among BRCA-wild type patients compared to the other two groups.

In our study, patients with BRCA-positive and BRCAwild type breast cancer were managed, in general, somewhat differently from patients with sporadic disease. In fact, BRCA-positive patients and, albeit to a lesser extent, BRCA-wild type patients underwent mastectomy more frequently than women with sporadic breast cancer. Although this tendency for mastectomy may be related to the bias of the patient and/or the surgeon rather than to BRCA mutation status, which was unknown at diagnosis, the choice of these procedures is also influenced by the patient's age and tumor phenotypic characteristics. Regarding systemic therapy, because BRCA-positive and BRCA-wild type breast cancer are more frequently steroid receptor-negative tumors, more BRCA-positive and BRCA wild type patients received adjuvant chemotherapy therapy than did sporadic breast cancer patients.

Despite the importance of family history as a risk factor for breast cancer [29], there is disagreement about its impact on prognosis of breast cancer patients with a strong family history associated or not to a BRCA mutation [30-33]. In our study, disease-free and overall survival did not differ significantly between women with BRCA-positive breast cancer and women with sporadic breast cancer. This is in line with reports that survival is not worse in patients with hereditary breast cancer, particularly if adjuvant chemotherapy is administered [34-39]. BRCA mutations render cancer cells more sensitive to DNA breaking agents such as alkylating agents and platinum salts, which are often used in adjuvant treatment. Most of our BRCA-mutation carriers received adjuvant chemotherapy. The increased susceptibility to and the very high rate of adjuvant chemotherapy among BRCA-mutation carriers in our series may have contributed to their not worse prognosis compared to patients with sporadic breast cancer. Interestingly, at multivariate analyses, overall survival was better in BRCA-wild type breast cancer patients than in patients with sporadic breast cancer. Further studies are needed to clarify the genetic background of these tumors and, eventually, to determine whether their increased genetic instability results in a better outcome of anticancer therapies.

In line with previous studies showing that BRCAmutated breast cancer patients have a strong lifetime risk of developing a second primary cancer [40-43], we found that the incidence of second primary cancers was significantly higher in BRCA-positive patients than in the other two groups. Not surprisingly, we also found that the most frequent second primary in BRCA carrier patients was breast cancer in the contralateral breast. Estimates of contralateral breast cancer incidence among BRCA mutated breast cancer patients varies from 15 to $40 \%$ within
10 years [39, 44-48]. None of our BRCA-positive patients underwent prophylactic bilateral mastectomy and rate of contralateral breast cancer in this subgroup was about $12 \%$.

Little is known about the contralateral breast cancer risk in women with BRCA-wild type breast cancer. However, despite the lack of its efficacy, prophylactic bilateral mastectomy after a first breast cancer is being increasingly requested not only by mutation carriers but also by patients with familial non-BRCA mutated breast cancer, especially if the family history strongly suggests hereditary disease [49-52]. In our series, the incidence of a second primary among BRCA-wild type patients was about $15 \%$. Most second primaries were contralateral breast cancer (14\%). This rate is higher than reported previously $[42,53]$. Several studies have shown that contralateral breast cancer risk in familial non-BRCA-mutated breast cancer patients varies depending on the patient's age at the first breast cancer diagnosis $[42,48,54]$. In fact, women older than 50 years when diagnosed with breast cancer had a significantly lower risk of contralateral breast cancer (cumulative incidence of contralateral breast cancer 12.9\%) than women diagnosed before the age of 40 years (cumulative incidence of contralateral breast cancer 28.4\%) [42, 48, 54]. In our BRCA-wild type patients, the young age at diagnosis (most patients were below the age of 45 years) and the absence of prophylactic bilateral mastectomy may have accounted for the increased incidence of contralateral breast cancer we found in this subgroup.

Our study has several strengths. It is a single institution study of the prognostic effects of BRCA mutations and a family history suggestive of hereditary disease on breast cancer outcome in women monitored for almost 15 years. All patients with a family history suggestive of hereditary disease underwent genetic counseling and risk assessment. Genetic testing was conducted only if the patient was considered at high risk for a BRCA mutation according to the clinical criteria of Modena [14] and BRCA pro [15, 16].

The limits of our study are the retrospective nature of the analyses and the relatively low numbers of BRCA1 and BRCA2 mutation carriers identified. Indeed, the stringent criteria used to decide whether to conduct genetic testing (genetic testing was carried out only if patients were considered at high risk for a BRCA mutation) and the prevalence of Caucasian not Ashkenazi patients may account for the relatively low incidence of BRCA mutation found in our dataset. Importantly, the low number of events that occurred in these carriers may have affected the precision of our analyses. Finally, we did not examine the effects of breast surgery (lumpectomy versus mastectomy) or of different types of adjuvant chemotherapies on locoregional events or other outcomes.

\section{Conclusions}

Breast cancers in BRCA-mutation carriers and BRCA-wild type patients differ from those in women with sporadic 
breast cancers in terms of age at presentation, hormone receptor and c-erbB2 status, type of local and systemic adjuvant therapy received and second primary incidence. These clinical and biological differences translated into outcome differences with a better overall survival in the BRCA-wild type patients than in patients with sporadic breast cancer. Notably, there was a high incidence of contralateral breast cancer in patients with BRCA-wild type breast cancer. Should these results be confirmed by other studies, prophylactic bilateral mastectomy may become a reasonable option in this subset of patients.

\section{Abbreviations \\ Cls: Confidence intervals; DFS: Disease free survival; ER: Estrogen receptor; HR: Hazard ratio; OS: Overall survival; PgR: Progesteron receptor}

\section{Acknowledgements}

We thank Jean Ann Gilder (Scientific Communication Srl, Naples, Italy) for revising and editing the manuscript.

\section{Funding}

Not applicable.

\section{Availability of data and materials}

The data that support the findings of this study are available from the corresponding author upon reasonable request.

\begin{abstract}
Authors' contributions
GA conceived the study, participated in its design and coordination and helped to draft the manuscript, MP participated in the design of the study and made a substantial contribution to the analysis and interpretation of data, CC participated in the design of the study, RR made substantial contributions to data acquisition and in drafting the manuscript, IC made substantial contributions to data acquisition and drafting the manuscript, RL participated in the design of the study, VF participated in the design of the study, MG participated in the design of the study, CDA participated in the design of the study, MM performed the statistical analysis, AC performed the statistical analysis, SDP gave final approval of the version to be published. All authors read and approved the final manuscript.
\end{abstract}

\section{Competing interests}

The authors declare that they have no competing interests.

\section{Consent for publication}

Not applicable.

\section{Ethics approval and consent to participate}

Institutional Review Board approval was waived as all patients signed informed consent to anonymous data treatment for scientific purpose according to Italian law (art.13, D.Igs. 196/2003).

\section{Author details}

'Department of Clinical Medicine and Surgery, University of Naples Federico II, Naples, Italy. ${ }^{2}$ The Lester and Sue Smith Breast Center, Baylor College of Medicine, Houston, Texas, USA. ${ }^{3}$ Department of Epidemiology, Istituto Nazionale Tumori Pascale, Naples, Italy.

Received: 12 November 2015 Accepted: 22 November 2016

Published online: 29 November 2016

\section{References}

1. Kleibl Z, Kristensen VN. Women at high risk of breast cancer: Molecular characteristics, clinical presentation and management. Breast. 2016;28:136-44.

2. Bordeleau Panchal S, Goodwin P. Prognosis of BRCA-associated breast cancer: a summary of evidence. Breast Cancer Res Treat. 2010;119(1):13-24.

3. Huzarski T, Byrski T, Gronwald J, Gorski B, Domagala P, Cybulski C, et al. Tenyear survival in patients with BRCA1-negative and BRCA1-positive breast cancer. J Clin Oncol. 2013;31:3191-6.
4. Foulkes WD, Chappuis PO, Wong N, Brunet JS, Vesprini D, Rozen F, Yuan ZQ, Pollak MN, Kuperstein G, Narod SA, Bégin LR. Primary node negative breast cancer in BRCA1 mutation carriers has a poor outcome. Ann Oncol. 2000;11:307-13.

5. Zhong Q, Peng HL, Zhao X, Zhang L, Hwang WT. Effects of BRCA1- and BRCA2-related mutations on ovarian and breast cancer survival: a meta-analysis. Clin Cancer Res. 2015;21(1):211-20.

6. Goodwin PJ, Phillips KA, West DW, Ennis M, Hopper JL, John EM, et al. Breast cancer prognosis in BRCA1 and BRCA2 mutation carriers: an International Prospective Breast Cancer Family Registry population-based cohort study. J Clin Oncol. 2012;30:19-26.

7. Cortesi L, Masini C, Cirilli C, Medici V, Marchi I, Cavazzini G, et al. Favourable ten-year overall survival in a Caucasian population with high probability of hereditary breast cancer. BMC Cancer. 2010;10:90.

8. Arason A, Gunnarsson H, Johannesdottir G, et al. Genome-wide search for breast cancer linkage in large Icelandic non-BRCA1/2 families. Breast Cancer Res. 2010;12(4):R50.

9. Snape K, Ruark E, Tarpey P, et al. Predisposition gene identication in common cancers by exome sequencing: insights from familial breast cancer. Breast Cancer Res Treat. 2012;134(1):429-33.

10. Gracia-Aznarez FJ, Fernandez V, Pita G, et al. Whole exome sequencing suggests much of non-BRCA1/BRCA2 familial breast cancer is due to moderate and low penetrance susceptibility alleles. PLoS One. 2013;8(2):e55681.

11. Hilbers FS, Meijers CM, Laros JF, et al. Exome sequencing of germline DNA from non-BRCA1/2 familial breast cancer cases selected on the basis of aCGH tumor pro ling. PLoS One. 2013;8(1):e55734.

12. Larsen MJ, Thomassen M, Gerdes AM, Kruse TA. Hereditary breast cancer : clinical, pathological and molecular characteristics. Breast Cancer. 2014;8:145-55.

13. Contegiacomo A, Pensabene M, Capuano I, Tauchmanova L, Federico M, Turchetti D, Cortesi L, Marchetti P, Ricevuto E, CianciG VS, Barbieri V, Silingardi V, Italian Network on Hereditary Breast Cancer. An Oncologistbased model of cancer genetic counseling for hereditary breast and ovarian cancer. Ann Oncol. 2004;15(5):726-32.

14. Cortesi L, Turchetti D, Marchi I, Fracca A, Canossi B, Rachele B, Silvia R, Rita PA, Pietro T, Massimo F. Breast cancer screening in women at increased risk according to different family histories: an update of the Modena Study Group experience. BMC Cancer. 2006;6:210.

15. Berry DA, Iversen Jr ES, Gudbjartsson DF Hiller EH, Garber JE, Peshkin BN, Lerman C, Watson P, Lynch HT, Hilsenbeck SG, Rubinstein WS, Hughes KS, Parmigiani G. BRCApro validation, sensitivity of genetic testing of BRCA1/2 and prevalence of other breast cancer susceptibility genes. J Clin Oncol. 2002;20(11):2701-12

16. Marroni F, Aretini P, D'AndreaE CMA, Cortesi L, Viel A, Ricevuto E, Montagna M, Cipollini G, Ferrari S, Santarosa M, BisegnaR B-WJE, Bevilacqua G, Parmigiani G, Presciuttini S. Evaluation of widely used models for predicting BRCA1 and BRCA2 mutations. J Med Genet. 2004:41:278-85.

17. American Society of Clinical Oncology. American Society of Clinical Oncology policy statement update: genetic testing for cancer susceptibility. JCO. 2003;21(15):2397-406.

18. Santi, et al. Linee guida per test genetici, Comitato Nazionale per la biosicurezza e per le biotecnologie. 1998. http://www.iss.it/scientifica/ pubblica/lineeguida/genetici.htm.

19. GenBank. http://www.ncbi.nlm.nih.gov/Genbank/index.html.

20. Breslow NE, Day NE. Statistical methods in cancer research. Volume II-The design and analysis of cohort studies. IARC Sci Publ. 1987;82:1-406.

21. Brekelmans CT, Tilanus-Linthorst MM, Seynaeve C, vd Ouweland A, MenkePluymers MB, Bartels CC, et al. Tumour characteristics, survival and prognostic factors of hereditary breast cancer from BRCA2-, BRCA1- and non-BRCA1/2 families as compared to sporadic breast cancer cases. Eur J Cancer. 2007:43:867-76.

22. Huzarski T, Byrski T, Gronwald J, Gorski B, Domagala P, Cybulski C, et al. Tenyear survival in patients with BRCA1-negative and BRCA1-positive breast cancer. J ClinOncol. 2013;31:3191-6.

23. Goodwin PJ, Phillips KA, West DW, Ennis M, Hopper JL, John EM, et al. Breast cancer prognosis in BRCA1 and BRCA2 mutation carriers: an International Prospective Breast Cancer Family Registry population-based cohort study. J ClinOncol. 2012;30:19-26.

24. Mavaddat N, Barrowdale D, Andrulis IL. Cancer Epidemiol Biomark Prev. 2012:21(1):134-47.

25. Van der Groep P, van der Wall E, van Diest PJ. Cell Oncol (Dordr). 2011:34(2):71-88.

26. Stratton MR. Lancet. 1997;349(9064):1505-10. 
27. Honrado E, Osorio A, Milne RL, et al. Immunohistochemical classification of non-BRCA1/2 tumors identies di erent groups that demonstrate the heterogeneity of BRCAX families. Mod Pathol. 2007;20(12):1298-306.

28. Lakhani SR, Gusterson BA, Jacquemier J, et al. e pathology of familial breast cancer: histological features of cancers in families not attributable to mutations in BRCA1 or BRCA2. Clin Cancer Res. 2000;6(3):782-9.

29. Couch FJ, Nathanson KL, Offit K. Two decades after BRCA: setting paradigms in personalized cancer care and prevention. Science. 2014;343(6178): $1466 \mathrm{e} 70$.

30. Albano W, Recabaren JA, Lynch HT, Campbell AS, Mailliard JA, Organ $\mathrm{CH}_{\text {, }}$ Lynch JF, Kimberling WJ. Natural history of hereditary cancer of the breast and colon. J Cancer. 1982;50(2):360-3.

31. Andersson D, Badzioch MD. Survival in familial breast cancer patients. Cancer. 1986;58(2):360-5.

32. Byrd LM, Shenton A, Maher ER, Woodward E, Belk R, Lim C, Lalloo F, Howell A, Jayson GC, Evans GD. Better life expectancy in women with BRCA2 compared with BRCA1 mutations is attributable to lower frequency and later onset of ovarian cancer. Cancer Epidemiol Biomark Prev. 2008;17(6):1535-42.

33. Chatterjee $\mathrm{N}$, Hartge $\mathrm{P}$, Wacholder $\mathrm{S}$. Adjustment for competing risk in kincohort estimation. Genet Epidemiol. 2003;25(4):303-13.

34. Liebens FP, Carly B, Pastijn A, Rozenberg S, et al. Management of BRCA1/2 associated breast cancer: a systematic qualitative review of the state of knowledge in 2006. Eur J Cancer. 2007;43(2):238-57.

35. Moller P, Evans DG, Reis MM, Gregory H, Anderson E, Maehle L, Lalloo F, Howell A, Apold J, Clark N, Lucassen A, Steel CM. Surveillance for familial breast cancer: Differences in outcome according to BRCA mutation status. Int J Cancer. 2007:121(5):1017-20.

36. Rennert G, Bisland-Naggan S, Barnett-Griness O, Bar-Joseph N, Zhang S, Rennert HS, Narod SA. Clinical outcomes of breast cancer in carriers of BRCA1 and BRCA2 mutations. N Engl J Med. 2007;357(2):115-23.

37. Robson ME, Chappuis PO, SatagopanJ WN, Boyd J, Goffin JR, Hudis C, Roberge D, Norton L, Bégin LR, Offit K, Foulkes WD. A combined analysis of outcome following breast cancer: differences in survival based on BRCA BRCA2 mutation status and administration of adjuvant treatment. Breast Cancer Res. 2004;6:R8-R17.

38. Foulkes WD, Wong N, Brunet JS, Bégin LR, Zhang JC, Martinez JJ, Rozen F, Tonin PN, Narod SA, Karp SE, Pollak MN. Germ-line BRCA1 mutation is an adverse prognostic factor in Ashkenazi Jewish women with breast cancer. Clin Cancer Res. 1997:3:2465-9.

39. Stoppa-Lyonnet D, Ansquer Y, Dreyfus H, Gautier C, Gauthier-Villars M, Bourstyn E, Clough KB, Magdelénat H, Pouillart P, Vincent-Salomon A, Fourquet A, Asselain B. Familial invasive breast cancers: worse outcome related to BRCA1 mutations. J Clin Oncol. 2000;18:4053-9.

40. Ford D, Easton DF, Stratton M, Narod S, Goldgar D, Devilee P, Bishop DT, Weber B, Lenoir G, Chang-Claude J, Sobol H, Teare MD, Struewing J, Arason A, Scherneck S, Peto J, Rebbeck TR, Tonin P, Neuhausen S, Barkardottir R, Eyfjord J, Lynch H, Ponder BA, Gayther SA, Zelada-Hedman M, et al. Genetic heterogeneity and penetrance analysis of the BRCA1 and BRCA2 genes in breast cancer families. The Breast Cancer Linkage Consortium. Am J Hum Genet. 1998;62(3):676-89.

41. Mersch J, Jackson MA, Park M, Nebgen D, Peterson SK, Singletary C, Arun BK Litton JK. Cancers associated with BRCA1 and BRCA2 mutations other than breast and ovarian. Cancer. 2015;121:269-275.

42. Rhiem K, Engel C, Graeser M, Zachariae S, Kast K, Kiechle M, Ditsch N, Janni W, Mundhenke C, Golatta M, Varga D, Preisler-Adams S, Heinrich T, Bick U, Gadzicki D, Briest S, Meindl A, Schmutzler RK. The risk of contralateral breast cancer in patients from BRCA1/2 negative high risk families as compared to patients from BRCA1 or BRCA2 positive families: a retrospective cohort study. Breast Cancer Res. 2012;14(6):R156.

43. Antoniou A, Pharoah PD, Narod S, Risch HA, Eyfjord JE, Hopper JL, Loman N, Olsson H, Johannsson O, Borg A, Pasini B, Radice P, Manoukian S, Eccles DM, Tang N, Olah E, Anton-Culver H, Warner E, Lubinski J, Gronwald J, Gorski B, Tulinius H, Thorlacius S, Eerola H, Nevanlinna H, Syrjäkoski K, Kallioniemi OP, Thompson D, Evans C, Peto J, et al. Average risk of breast and ovarian cancer associated with BRCA1 or BRCA2 mutations detected in case series unselected for family history: a combined analysis of 22 studies. Am J Hum Genet. 2003;72:1117.

44. Tehillah S. Menes. Breast Cancer Res Treat. 2015;151(3):653-60.

45. Pierce LJ, Levin AM, Rebbeck TR, Ben-David MA, Friedman E, Solin LJ, Harris EE, Gaffney DK, Haffty BG, Dawson LA, NarodSA OIA, Eisen A, Whelan TJ, Olopade OI, Isaacs C, Merajver SD, Wong JS, Garber JE, Weber BL. Ten-year multi-institutional results of breast-conserving surgery and radiotherapy in BRCA1/2-associated stage I/II breast cancer. J Clin Oncol. 2006;24(16):2437-43.

46. Pierce $L$, Haffty BG. Radiotherapy in the treatment of hereditary breast cancer. Semin Radiat Oncol. 2011;21(1):43-50.

47. Graeser MK, Engel C, Rhiem K, Gadzicki D, Bick U, Kast K, Froster UG, Schlehe B, Bechtold A, Arnold N, Preisler-Adams S, Nestle-Kraemling C, Zaino M, Loeffler M, Kiechle M, Meindl A, Varga D, Schmutzler RK. Contralateral breast cancer risk in BRCA1 and BRCA2 mutation carriers. J ClinOncol. 2009;27(35):5887-92.

48. Metcalfe K, Gershman S, Lynch HT, Ghadirian P, Tung N, Kim-Sing C, Olopade OI, Domchek S, McLennan J, Eisen A, Foulkes WD, Rosen B, Sun P, Narod SA. Predictors of contralateral breast cancer in BRCA1 and BRCA2 mutation carriers. Br J Cancer. 2011;104(9):1384-92.

49. Rosenberg SM, Sepucha K, Ruddy KJ, Tamimi RM, Gelber S, Meyer ME, Schapira L, Come SE, Borges VF, Golshan M, Winer EP, Partridge AH. Local therapy decision-making and contralateral prophylactic mastectomy in young women with early-stage breast cancer. Ann Surg Oncol. 2015;22(12):3809-15.

50. Reiner AS, John EM. Risk of asynchronous contralateral breast cancer in noncarriers of BRCA1 and BRCA2 mutations with a family history of breast cancer: a report from the Women's Environmental Cancer and Radiation Epidemiology Study. JCO. 2013;31(4):433-9. doi:10.1200/JCO.2012.43.2013.

51. King TA, Sakr R, Patil S, Gurevich I, Stempel M, Sampson M, Morrow M. Clinical management factors contribute to the decision for contralateral prophylactic mastectomy. J Clin Oncol. 2011;29(16):2158-64.

52. Khan SA. Contralateral prophylactic mastectomy: what do we know and what do our patients know? J Clin Oncol. 2011;29(16):2132-5.

53. Boughey JC, Hoskin TL, Degnim AC, Sellers TA, Johnson JL, Kasner MJ, Hartmann LC, Frost MH. Contralateral prophylactic mastectomy is associated with a survival advantage in high-risk women with a personal history of breast cancer. Ann Surg Oncol. 2010;17(10):2702-9.

54. Tilanus-Linthorst MM, Bartels KC, Alves C, Bakri B, Crepin E, van den Ouweland A, Klijn JG, Meijers-Heijboer H, Brekelmans CT. Selection bias influences reported contralateral breast cancer incidence and survival in high risk non-BRCA1/2 patients. Breast Cancer Res Treat. 2006;95(2):117-23.

\section{Submit your next manuscript to BioMed Central and we will help you at every step:}

- We accept pre-submission inquiries

- Our selector tool helps you to find the most relevant journal

- We provide round the clock customer support

- Convenient online submission

- Thorough peer review

- Inclusion in PubMed and all major indexing services

- Maximum visibility for your research

Submit your manuscript at www.biomedcentral.com/submit
C Biomed Central 